\title{
Physical Properties and Biodegradabilities of the PLA/ Soy-Oil Blends and Their Ramie Fiber Composites
}

\author{
Jong Sung Won ${ }^{1}$, Min Jun Lee ${ }^{2}$, Pil Gyu Lee ${ }^{2}$ and Seung Goo Lee ${ }^{2 *}$ \\ ${ }^{1}$ Robert Frederick Smith School of Chemical and Biomolecular Engineering, Cornell University, USA \\ ${ }^{2}$ Department of Advanced Organic Materials \& Textile System Engineering, Chungnam National University, Republic of Korea
}

*Corresponding author: Seung Goo Lee, Department of Advanced Organic Materials \& Textile System Engineering, Chungnam National University, Daejeon 34134, Republic of Korea.

Received Date: October 26, 2020

Published Date: November 09, 2020

\begin{abstract}
A bio-based composite material was developed from soy-based bioplastic and natural fibers. This eco-friendly composite can be a substitute for petroleum-based composite materials. In this study, biodegradable composites based on the modified soybean oil and ramie fiber were prepared with various content of epoxidized soybean oil (ESO), acrylated epoxidized soybean oil (AESO), maleated acrylated soybean oil (MASO) and PLA. As a result, by blending with ESO, AESO and MASO, flexibility of PLA was largely enhanced. Also, deterioration of mechanical properties was prevented when the PLA/soybean oil blend was quenched in cold water. The Biodegradabilities of neat PLA and blends (PLA/ESO, PLA/AESO and PLA/ESO/ AESO) and their ramie fiber reinforced composites were retarded by adding ESO and AESO.
\end{abstract}

Keywords: PLA; Soybean oil; Ramie fiber; Composite; Biodegradability; Fiber reinforced composite

\section{Introduction}

Biodegradable or environmentally acceptable materials have attained increasing interest over the past decades due to environmental pressure derived from the consumption of petroleum-based materials [1-3]. As a natural polymer from natural resources, soybean has been regarded as an alternative material to petroleum plastic because it is abundant, renewable, inexpensive and environmentally friendly. However, the performance of soy plastic derived from soy protein is still lower than other commonly used plastics for application. Therefore, some reinforcing is essential to PLA a simple and effective way is using natural fibers as reinforcement because of their many advantages such as low cost, low density, good specific strength properties, biodegradability as well as excellent sonic insulation properties [4-8].

Natural plant-based cellulose fibers such as flax, hemp, jute, sisal, henequen and ramie have gained importance in recent years as a reinforcing component in both thermoplastic and thermoset matrix composites. Compared to synthetic fibers, natural plant- based fibers have several specific advantages. Biocomposites which are composed of natural fibers with synthetic or natural polymer matrix have recently gained much attention due to their low cost, low density, ready availability, possible biodegradability, enhanced energy recovery and CO2 sequestration [9-16].

On the other hand, vegetable oils such as soybean oil, linseed oil, palm oil, rapeseed oil, etc. are represented to the major class of natural resources and they are being used in an increasing number of industrial applications. Soybean oil is one of the cheapest and most abundant biological oil containing triglyceride. Triglycerides are composed of saturated and/or unsaturated fatty acids connected by glycerol through ester linkages and have $\sim 4.5$ nonconjugated $\mathrm{C}=\mathrm{C}$ bonds. These double bonds may be converted into the oxirane moiety by reaction with peracids or peroxides [17-19].

In this study, acrylated, epoxidized, and maleated soy bean oils were prepared for blending with PLA resin. The effects of heat treatment on the properties of the PLA/soybean oil blends 
were investigated. Then using the blends, ramie fiber reinforced composites were manufactured and analyzed. In the compost condition, weight loss as time of each resin and composite was examined for estimating biodegradability.

\section{Materials and Methods}

\section{Materials}

$100 \%$ edible soybean oil (SO) and epoxidized soybean oil (ESO) were obtained from CJ cheil chedang and Sinwon chemical Co. Ltd, respectively. Acrylated epoxidized soybean oil (AESO) was obtained from Sigma-Aldrich Co. Also, maleated acrylated soybean oil (MASO) was synthesized using hydroquinone, maleic anhydride, and N,N-dimethylbenzylamine (DMBA) by Wool's presented method [20]. Firstly, AESO $(1,200 \mathrm{~g} / \mathrm{mol})$ of $100 \mathrm{~g}$ and $0.01 \mathrm{wt} \%$ hydroquinone was mixed in the flask and was heated to $70^{\circ} \mathrm{C}$ stirring under the nitrogen atmosphere. After that, we had put maleic anhydride $(98 \mathrm{~g} / \mathrm{mol})$ of $16 \mathrm{~g}$ in the flask at $80 \sim 85{ }^{\circ} \mathrm{C}$. Then, the two were mixed completely, putting the DMBA of $2 \mathrm{~g}$ as a catalyst, and they reacted for 2 hours to synthesize the MASO.

Specific gravity and melting temperature of the PLA(polymer 6201D, Nature Works) which was used for blending were 1.4 and $170{ }^{\circ} \mathrm{C}$, respectively. Ramie fiber was obtained from Dong-il Co. Before using it, pretreating process such as chopping, dewaxing, degumming, beating, and acetylation was conducted

\section{Preparation of PLA / soybean oil blend and composite}

Each modified PLA/soybean oil blend was mixed using a Brabender mixer of $5,10,15 \mathrm{wt} \%$, respectively, at $190{ }^{\circ} \mathrm{C}$ under 90rpm. Each blend was molded using a hot press under 2,000psi at $190{ }^{\circ} \mathrm{C}$ for 10 minutes and then quenched to room temperature in cold water. Composite that composed of modified PLA/soybean oil blend resin and ramie fiber of 10, 20, and 30wt\% were manufactured using a blending mixer and molded by the abovementioned method.

\section{Thermal properties}

To estimate the change of glass transition temperature with modified soybean oil content, each specimen was cut into $12.5 \times$ $35 \mathrm{~mm}$ with a thickness of $2 \mathrm{~mm}$. Dynamic mechanical analysis (DMA,
TA Instrument) was conducted in the temperature range from $25^{\circ} \mathrm{C}$ to $100^{\circ} \mathrm{C}$ with a heating rate of $5^{\circ} \mathrm{C} / \mathrm{min}$ under frequency of $1 \mathrm{~Hz}$ and amplitude of 20. Also, thermal stability and crystallization properties of the blend were analyzed using a thermogravimetric analysis (TGA) and differential scanning calorimeter (DSC), respectively, from TA Instrument. In the DSC analysis, specimens were heated to $140^{\circ} \mathrm{C}$, crystallization temperature of the PLA, and were slowly cooled to lead crystallization of each specimen. Change of crystallization temperature of the specimen as thermal treatment were analyzed with heating rate of $5^{\circ} \mathrm{C} / \mathrm{min}$.

\section{Mechanical properties}

To investigate the mechanical properties of modified PLA/ soybean oil blend and composite, tensile and flexural (three-point bend) tests were performed at a cross-head speed of $5 \mathrm{~mm} / \mathrm{min}$ using an Instron (Model 4467) according to ASTM D638 and ASTM D790, respectively. Each value of mechanical properties was an average of results of ten specimens.

\section{Morphology}

Fractured morphologies of modified PLA/soybean oil blend were observed with a scanning electron microscope (SEM, S4700, HITACHI).

\section{Crystallization properties}

Crystalline properties of modified PLA/soybean oil blend with thermal treatment condition were investigated by an XRD (Brukier, AXS, Germany).

\section{Biodegradability}

Modified PLA/soybean oil blend and composite were prepared with the size of $20 \mathrm{~mm} \times 20 \mathrm{~mm}$, respectively. They were dried in a vacuum oven for 2 hours. Specimens were mixed with the compost in the test bath (as shown in Figure 1) at $58 \pm 2{ }^{\circ} \mathrm{C}$, using a constant temperature controller. Furthermore, in order to maintain the aerobic environment, air was injected at $200 \mathrm{cc} / \mathrm{min}$ continuously during the test. With the elapsed time in a composting environment, the weight changes of the specimen were measured after drying in a vacuum oven for 12 hours at $50{ }^{\circ} \mathrm{C}$. Weight of specimens was measured up to 50days.

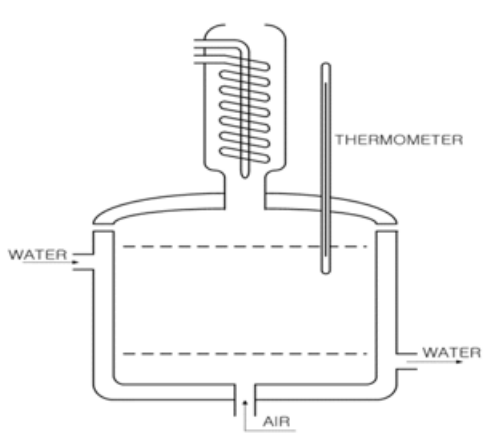

Figure 1: Schematic diagram of biodegradation test chamber. 


\section{Results and Discussion}

\section{Properties of modified PLA /soybean oil blend}

Thermal properties: Figure 2 shows TGA curves of the blend with content of ESO, AESO, and MASO. The difference in weight loss of the blend was occurred with the content of the modified soybean oil, but thermal stability was not changed due to the cross-linking of ESO, AESO and MASO. In the case of ESO, onset temperature of thermal degradation decreased at about $10^{\circ} \mathrm{C}$. However, there were no big changes in onset temperature in the blend of AESO and MASO. The results of tan delta are shown in Figure 3. Glass transition temperature of neat PLA is $70.08^{\circ} \mathrm{C}$, decreasing at $67.40,64.93$, and $64.58{ }^{\circ} \mathrm{C}$ as ESO content increased. In Figure 3(b), as AESO content increases to 5,10 , and $15 \mathrm{wt} \%$, tan delta decreases to $66.32,66.10$, and 65.19. In Figure 3(c), as MASO content increases, tan delta decreased to $67.34,65.44$, and $63.35^{\circ} \mathrm{C}$. From these results, it is considered that energy dissipation of the modified PLA/ soybean oil blend increases due to the amorphous feature.

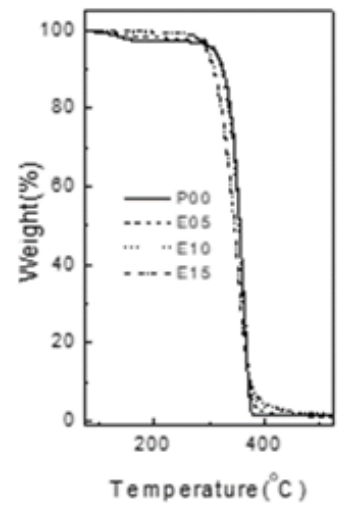

(a)

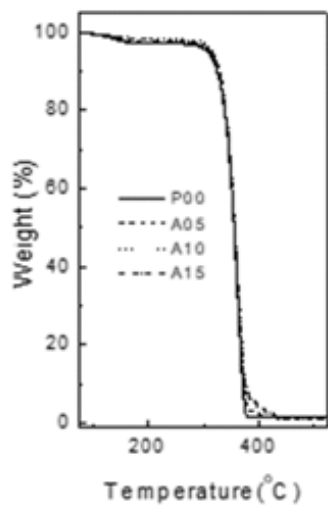

(b)

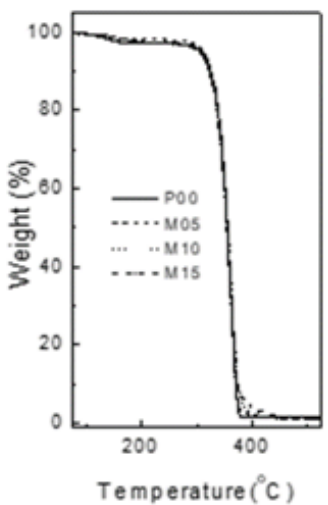

(c)

Figure 2: TGA results of blended PLA with various content of (a)ESO, (b)AESO and (c)MASO.

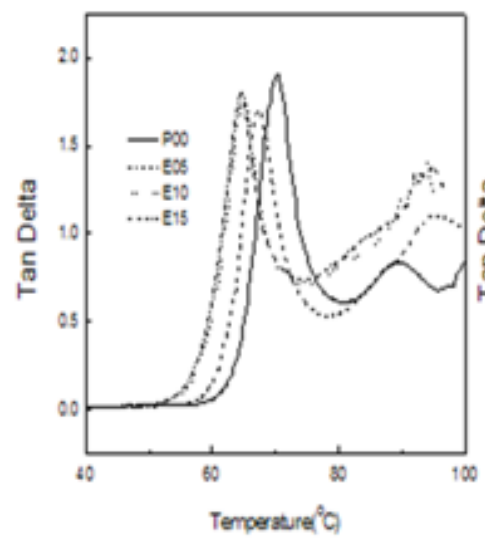

(a)

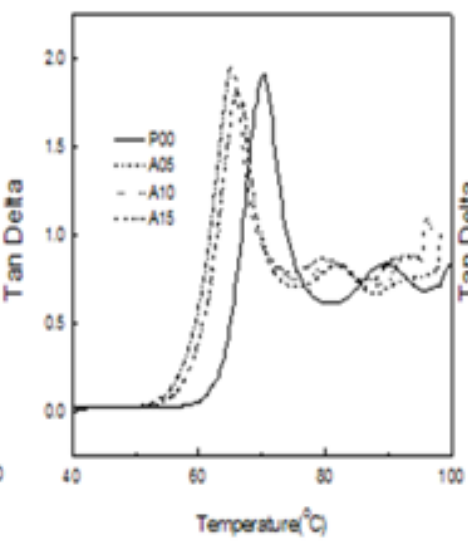

(b)

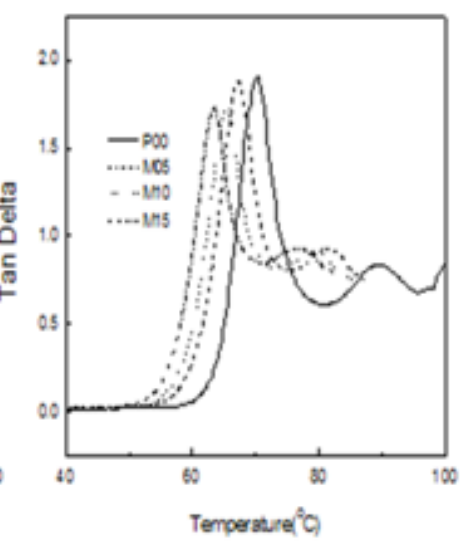

(c)

Figure 3: DMA overlaid tan delta of neat PLA and blended PLA with various content of (a)ESO, (b)AESO and (c)MASO.

Mechanical properties: Figure 4(a) shows tensile properties of the PLA/ESO blend having 5, 10 and 15wt\% of ESO. Tensile strength of neat PLA is 66.7MPa and as ESO content increases 5, 10 , and $15 \mathrm{wt} \%$, tensile strength of the blend decreases to 52.9 , 42.2, and 36.3MPa, respectively. However, an increase of ESO content leads very high elongation. Also, tensile properties of PLA decreased with AESO content, as shown in Figure 4(b). At $15 \mathrm{wt} \%$ AESO content, tensile strength was $38.2 \mathrm{MPa}$, while its elongation was $85 \%$. Figure 4 (c) shows tensile properties of the PLA/MASO blend modified with 5,10 , and $15 \mathrm{wt} \%$ of MASO. Tensile properties of the blend decreased with increasing MASO content and were higher than those of PLA/ESO and PLA/EASO blend. However, elongation was small with a brittle behavior.

Morphology: The SEM micrograph of the fractured surface after tensile test of neat PLA was shown in Figure 5(a) with a brittle fractured morphology. Figure 6 shows the SEM micrographs of fractured surface after tensile test of blended PLA with ESO, AESO, and MASO. The number of micro-pits were observed with the phase separation of ESO and AESO. However, in the PLA/MASO blend in 
Figure 5(d), micro-pits were not observed. It was reported that maleate group of MASO might form a cross-linked bond with PLA. MA is highly reactive with PLA free radicals induced by an initiator, the carboxylic groups, arising from the hydrolyzed anhydride, could also form hydrogen bonding with the hydroxyl groups [21].

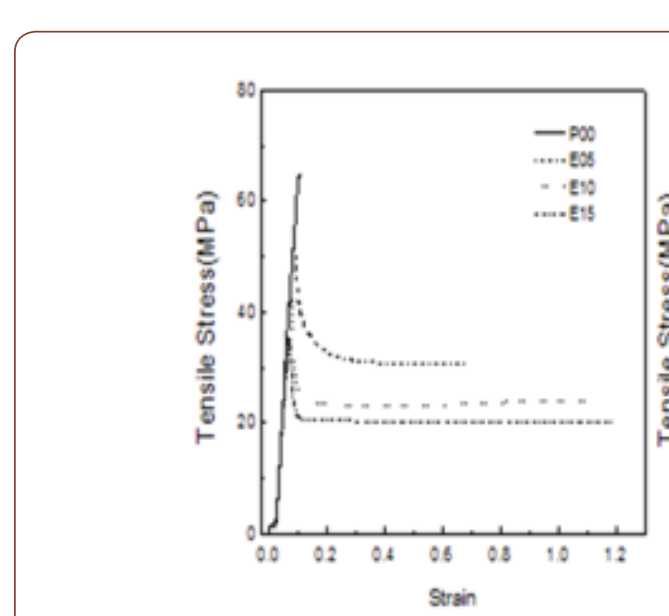

(a)

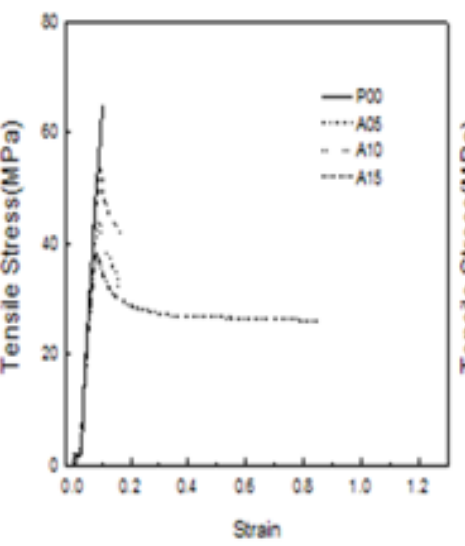

(b)

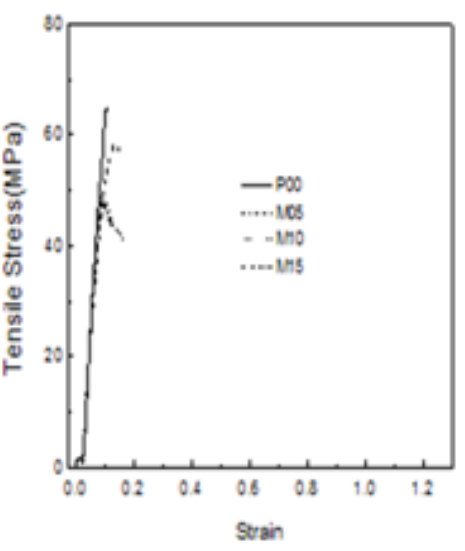

(c)

Figure 4: Tensile properties of neat PLA and blended PLA with various content of (a)ESO, (b)AESO and (c)MASO.

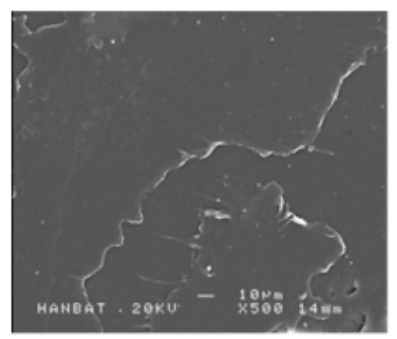

(a)

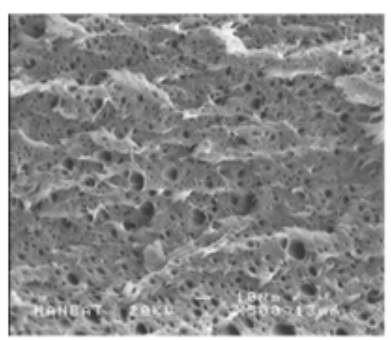

(c)

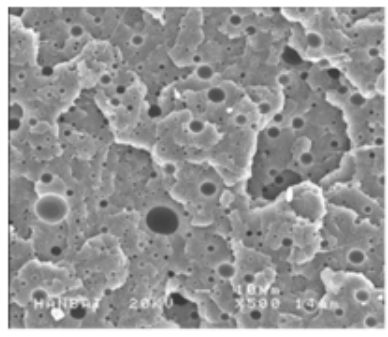

(b)

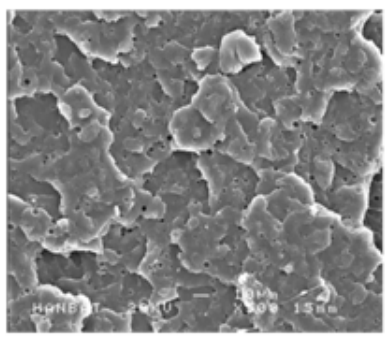

(d)

Figure 5: SEM images of tensile fracture surface of blended PLA with 15wt\% of (a)neat PLA, (b)ESO, (c)AESO and (d)MASO.

\section{Properties of modified PLA/soybean oil blend}

Crystallization temperature: Crystallization temperature of the modified PLA/soybean oil blend was evaluated from the DSC measurement according to the procedure given in the experimental section. Crystallization temperature of the neat PLA and the modified PLA/soybean oil blend was shown in Figure 6. Clearly, crystallization temperature of the modified PLA/soybean oil blend was largely lowered than that of the pure PLA, confirming that the crystallization of the PLA was hindered by the addition of ESO and AESO.
Crystallinity: Figure 7 shows the X-ray diffraction patterns of the modified PLA/soybean oil blend with the content of ESO, AESO and MASO. In order to compare the degree of crystallinity, all specimens were quenched in cold water. As the results, all blends showed amorphous features as shown in Figure 7.

Figure 8 shows the X-ray diffraction patterns of PLA/soybean oil blend after heat treatment at $140^{\circ} \mathrm{C}$. PLA/ESO and PLA/AESO blend of Figure 8 (a) and (b) show that the degree of crystallinity decreases with an increase of ESO and AESO content. These results suggest that the added ESO and AESO can lower the degree of 
crystallinity of a blend. The degree of crystallinity of the PLA/ soybean oil blend calculated from the XRD data was shown in Table 1. Contrastingly, PLA/MASO blend of Figure 8(c) shows that the degree of crystallinity increases with increasing content of MASO.
In this case, it can be suggested that the increase of crystallinity of PLA was due to the highly reactive MASO which can play an important role as a nucleating agent.
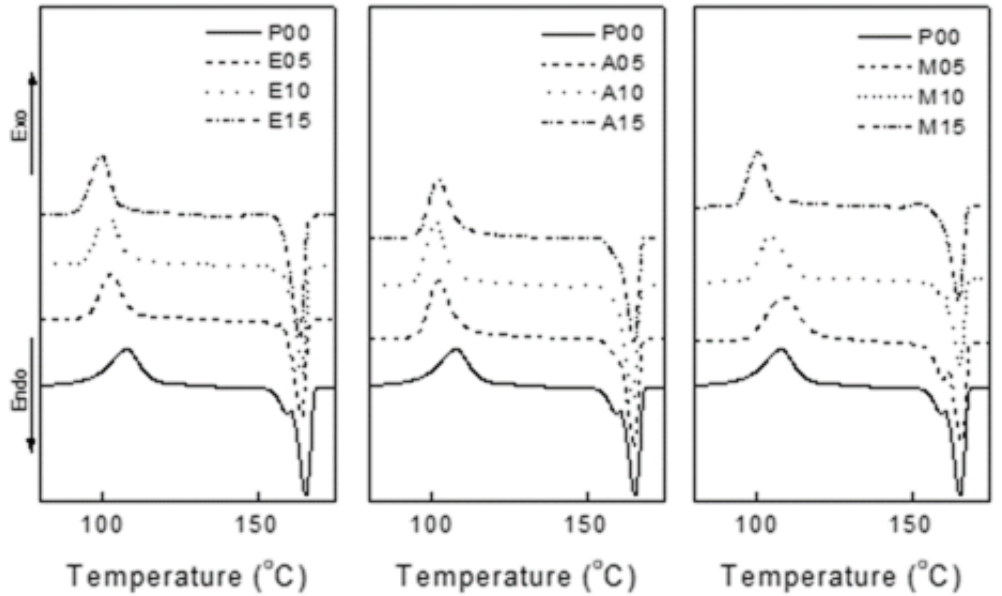

Figure 6: DSC results of heat-treated neat PLA and blends with various content of modified soybean oils: (a)ESO; (b)AESO; (c)MASO.

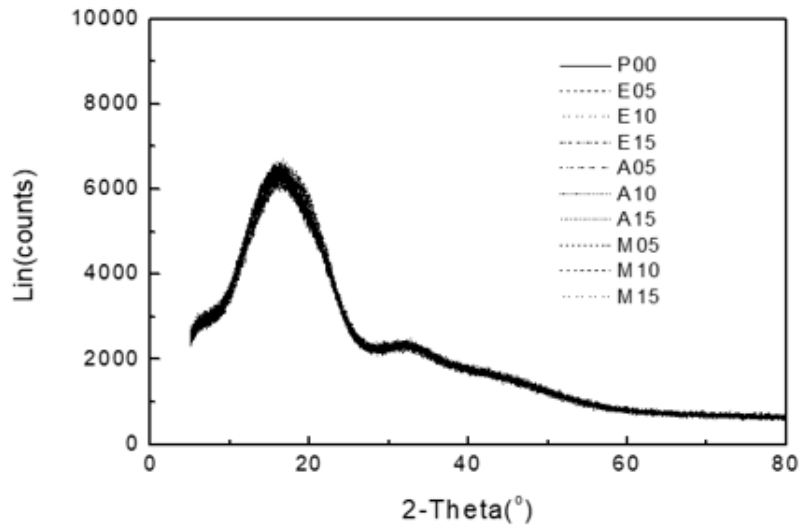

Figure 7: XRD results of quenched PLA and blends.

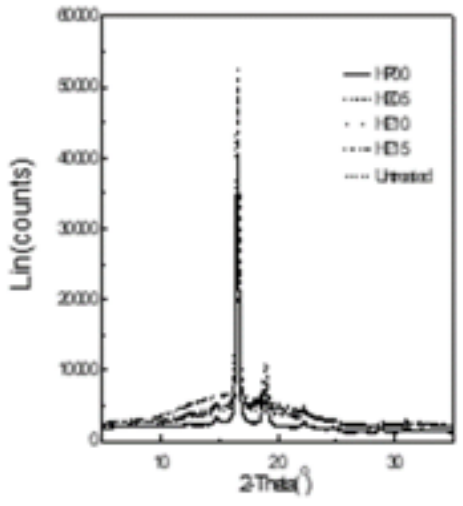

(a)

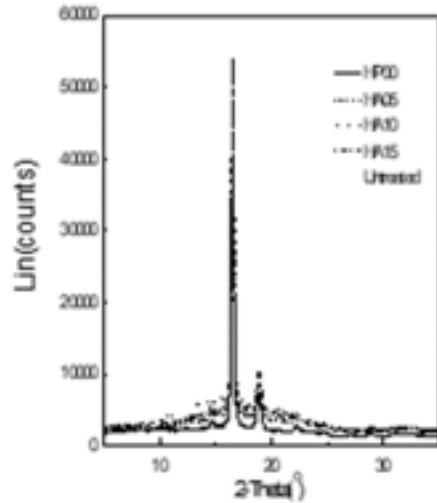

(b)

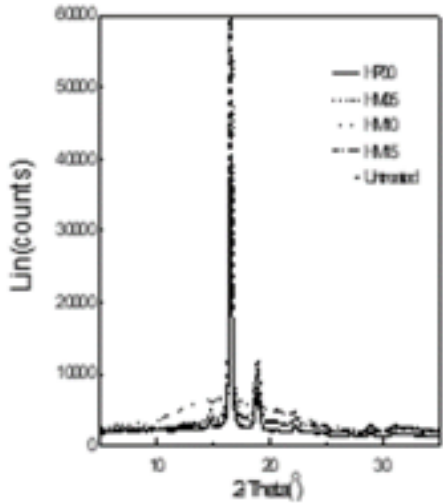

(c)

Figure 8: XRD peaks of heat-treated PLA/soybean oil blend: (a)PLA/ESO blend; (b)PLA/AESO blend; (c)PLA/MASO blend. 
Table 1: The degree of crystallinity of the PLA/modified soybean oil blend.

\begin{tabular}{|c|c|c|c|}
\hline \multirow{2}{*}{ Blends } & \multicolumn{3}{|c|}{ Soybean oil content } \\
\cline { 2 - 4 } & $5 \mathrm{wt} \%$ & $10 \mathrm{wt} \%$ & $15 \mathrm{wt} \%$ \\
\hline PLA/ESO & 45.5 & 42.3 & 32.3 \\
\hline PLA/AESO & 43.8 & 41.6 & 32.1 \\
\hline PLA/MASO & 54.4 & 50.3 & 46.2 \\
\hline
\end{tabular}

Tensile properties: Figure 9 shows changes of tensile strength after quenched and heat-treated PLA/soybean oil blend. Most of tensile strengths decreased with addition of ESO, AESO and MASO. Also, tensile strength of heat-treated neat PLA decreased about $47 \%$ than that of the quenched neat PLA. Tensile strength of PLA/ ESO and PLA/AESO blend slightly decreased in comparison to neat
PLA. But, tensile strength of PLA/MASO blend decreased largely than that of the neat PLA. From the above results, inclusion of MASO does not give good effects such as toughening and reinforcing to the PLA blend. Therefore, except MASO, ESO and AESO were chosen as optimum resins for manufacturing the ramie fiber reinforced composite.

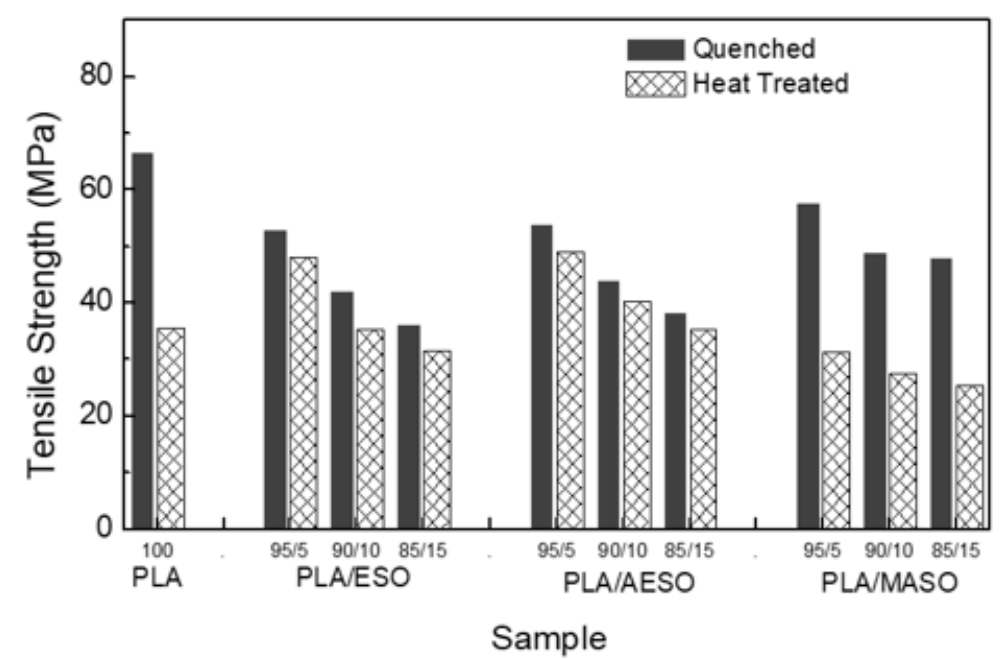

Figure 9: Tensile strengths of quenched and heat-treated blends.

Flexural properties: Figure 10 shows flexural strength of neat PLA, PLA/ESO (9:1) and PLA/AESO (9:1) blend. Similar to tensile behaviors, flexural strength of the blend decreased with the inclusion of modified soybean resin. However, the flexural deformation of neat PLA increased by addition of ESO and AESO.

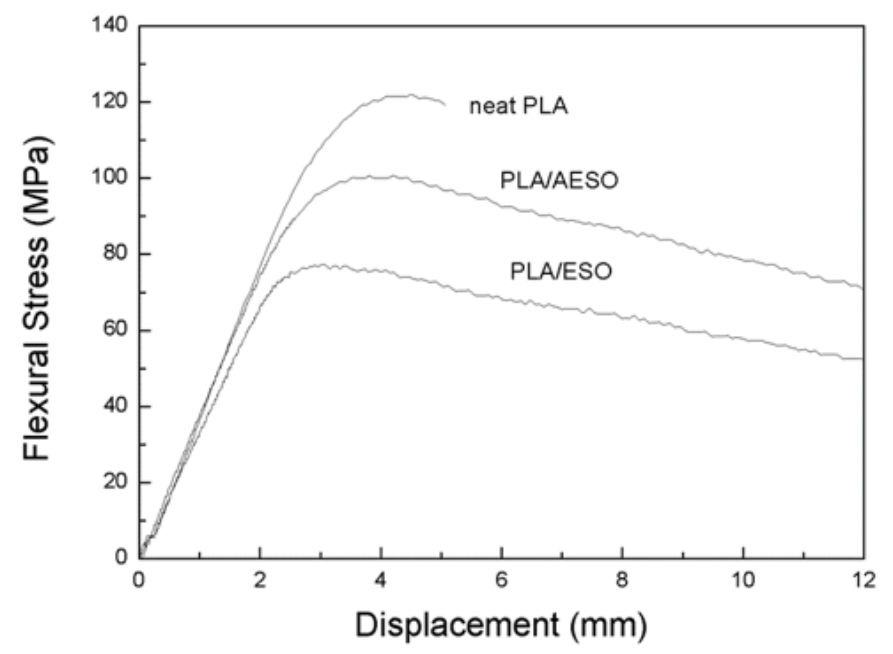

Figure 10: Flexural stress of neat PLA, PLA/ESO(9:1) and PLA/AESO(9:1) blend. 
Biodegradation properties: The weight changes of each neat PLA, PLA/ESO and PLA/AESO blend specimen according to biodegradability are shown in Figure 11. All specimens did not show the weight change during $2 \sim 3$ days, but PLA and modified PLA/soybean oil blend showed noticeable weight loss after 3 days
(AESO) and 7 days (ESO), respectively. After a month, PLA, PLA/ ESO and PLA/AESO blend showed the weight loss of 2.15\%, $0.99 \%$ and $1.85 \%$, respectively. After 50 days, the weight loss increased remarkably to $3.98 \%, 1.85 \%$ and $3.26 \%$ due to biodegradation.

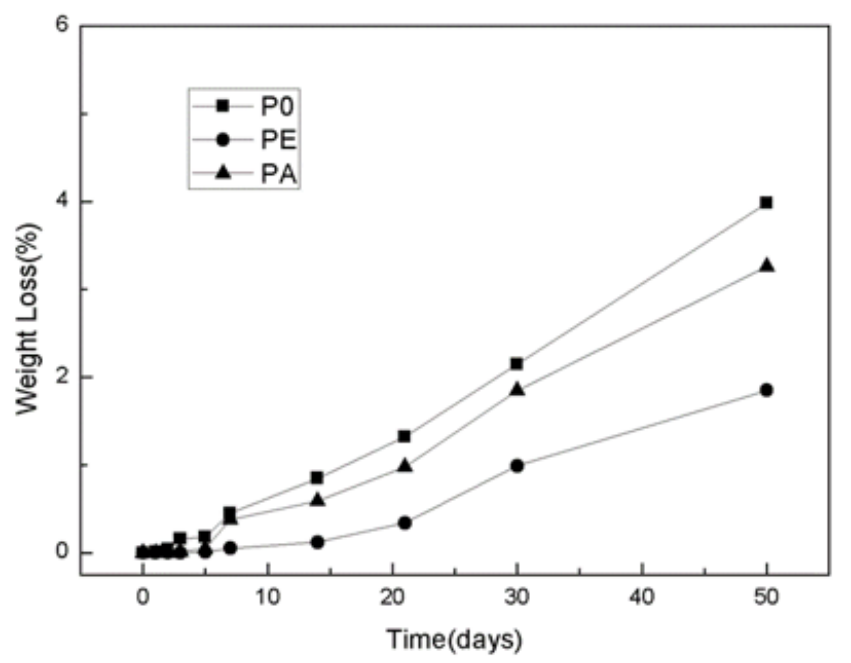

Figure 11: Weight loss of neat PLA and blended PLA (PE=PLA/ESO, PA=PLA/AESO) in compost.

\section{Ramie fiber reinforced PLA/soybean oil composite}

Biodegradation properties: The weight changes of each ramie fiber reinforced PLA, PLA/ESO and PLA/AESO composite according to biodegradability are shown in Figure 12. Weight loss by biodegradation of ramie fiber reinforced composite appeared after 1 day and was faster than that of the PLA blend. This behavior originated from the existence of ramie fiber having some residual moisture. That is, residual moisture in ramie fiber promotes the hydrolysis and biodegradation of the PLA/soy-oil matrix. On the other hand, degradation rate of the composite of PLA/ESO was slower than that of the PLA/AESO composite due to higher crystallinity as described above. It is suggested that the inclusion of the ESO in the composite might retard the biodegradation of the PLA.

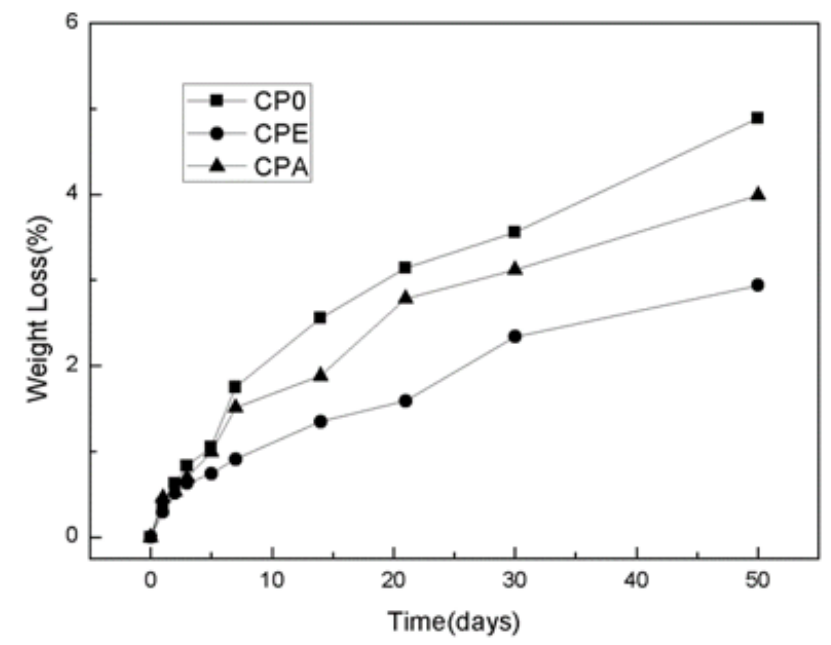

Figure 12: Weight loss of ramie fiber reinforced composites with various matrix resins (neat PLA and blended PLA) in compost.

\section{Conclusions}

In this study, the PLA/soybean oil blend and ramie fiber reinforced PLA/soybean oil composite were prepared with PLA,
ESO, AESO and MASO. Their thermal, mechanical and biodegradable properties were analyzed, and some results were obtained as follows; 
- $\quad$ By blending with ESO, AESO and MASO, tensile elongation of the PLA was enhanced largely. Deterioration of mechanical properties was prevented when the PLA/soybean oil was quenched in cold water.

- The PLA/MASO blend shows that the degree of crystallinity increases with increasing content of MASO. It can be suggested that the increase of crystallinity of PLA was due to the highly reactive MASO as a nucleating agent.

- The Biodegradabilities of PLA and its ramie fiber composites were retarded by adding ESO and AESO. Also, weight loss of ramie fiber reinforced composite appeared after 1 day and it was faster than that of the PLA blend. This behavior originated from the residual moisture in ramie fiber which can promote the hydrolysis and biodegradation of the PLA/soy-oil matrix.

\section{Acknowledgement}

This research project was sponsored by Chungnam National University.

\section{Conflict of Interest}

The authors declared no potential conflicts of interest with respect to the research, authorship, and /or publication of this article.

\section{References}

1. O’Donnell A, Dweib MA, Wool RP (2004) Natural fiber composites with plant oil-based resin. Composite Science and Technology 64(9): 11351145 .

2. Zhu J, Chandrashekhara K, Flanigan V (2004) Curing and mechanical characterization of a soy-based epoxy resin system. Journal of Applied Polymer Science 91(6): 3513-3518.

3. Liu Z, Erhan SZ, Akin DE, Barton FE (2006) "Green" composites form renewable resources: preparation of epoxidized soybean oil and flax fiber composites. J Agric Food Chem 54(6): 2134-2137.

4. Labrecque LV, Kumar RA, Dave V, Gross RA, Mccarthy SP (1997) Citrate esters as plasticizers for poly(lactic acid). Journal of Applied Polymer Science 66(8): 1507-1513.

5. Martin 0, Avérous L (2001) Poly(lactic acid): plasticization and properties of biodegradable multiphase systems. Polymer 42(14): 62096219.
6. Jacobsen S, Fritz HG (1999) Plasticizing polylactide-the effect of different plasticizers on the mechanical properties. Polymer Engineering \& Science 39(7): 1303-1310.

7. Liungberg N, Wesslen B (2002) The effects of plasticizers on the dynamic mechanical and thermal properties of poly(lactic acid). Journal of Applied Polymer Science 86(5): 1227-1234

8. Liungberg N, Wesslén B (2005) Preparation and properties of plasticized poly(lactic acid) films. Biomacromolecules 6(3): 1789-1796.

9. Won JS, Lee JE, Jin DY, Lee SG (2015) Mechanical Properties and Biodegradability of the Kenaf/Soy Protein Isolate-PVA Biocomposites. International Journal of Polymer Science 860617: 1-11.

10. Mohanty AK, Misra M, Hinrichsen G (2000) Biofibers, Biodegradable polymer and biocomposites. Macromol Materials and Engineering 276277(1): 1-24

11. Bledzki AK, Gassan J (1999) Composites reinforced with cellulose based fibers. Progress in Polymer Science 24(2): 221-274.

12. Mishra S, Mohanty AK, Drzal LT, Misra M, Parija S, et al. (2001) Study on mechanical performance of biofiber/glass reinforced polyester hybrid composites. Composite Science and Technology 61(6): 2519-2529.

13. Petruccelli S, Añón MC (1996) pH-induced modifications in the thermal stability of soybean protein isolates. Journal of Agricultural and Food Chemistry 44(10): 3005-3009.

14. Zhang Y, Ghasemzadeh S, Kotliar AM, Kumar S, Presnell S, et al. (1999) Fibers from soybean protein and poly(vinyl alcohol). Journal of Applied Polymer Science 71(1): 11-19.

15. Won JS, Lee TS, Kim HS, Son HG, Hong TM, et al. (2014) Preparation and Characterization of Kenaf/Soy Protein Biocomposites. Journal of Biobased Materials and Bioenergy 8(2): 221-229.

16. Matsuda S, Iwata H, Se N, Ikada Y (1999) Bioadhesion of gelatin films cross-linked with glutaraldehyde. J Biomed Mater Res 45(1): 20-27.

17. Gautam R, Bassi AS, Yanful EK (2007) A review of biodegradation of synthetic plastic and foams. Appl Biochem Biotechnol 141(1): 85-108.

18. Campanella A, La Scala JJ, Wool RP (2009) The use of acrylated fatty acid methyl esters as styrene replacements in triglyceride-based thermosetting polymers. Polymer Engineering \& Science 49(12): 23842392.

19. Williams GI, Wool RP (2000) Composites from natural fibers and soy oil resins. Applied Composite Materials 7: 421-432.

20. Tran P, Graiver D, Narayzn R (2006) Biocomposites synthesized from chemically modified soy oil and biofibers. Journal of Applied Polymer Science 102(1): 69-75.

21. Zhang JF, Sun X (2004) Mechanical properties of poly(lactic acid)/starch composites compatibilized by maleic anhydride. Biomacromolecules 5(4): 1446-1451. 